\title{
Molecular variability of Apple chlorotic leaf spot virus isolated in Belarus
}

\author{
P. Kuzmitskaya ${ }^{1 *}$, V. Titok ${ }^{2}$, B. Anoshenko², O. Urbanovich ${ }^{1}$ \\ ${ }^{1}$ Institute of Genetics and Cytology of National Academy of Science of Belarus, 27 Akademicheskaya Str., Minsk 220072, Belarus \\ ${ }^{2}$ Central Botanical Garden of National Academy of Science of Belarus, 2c Surganov Str., Minsk 220012, Belarus \\ *Corresponding author, E-mail: p.kuzmitskaya@igc.by
}

\begin{abstract}
Apple chlorotic leaf spot virus (ACLSV) is a harmful latent pathogen distributed worldwide in apple orchards. To evaluate the genetic diversity of this virus in Belarusian apple orchards, $850 \mathrm{bp}$ genome fragments coding parts of replicase and movement protein open reading frames from five viral isolates from apple in Belarus were sequenced. High genetic variability was detected among isolates studied. The potential sites of recombination were identified in the partial sequences of the replicase and movement protein genes of ASLSV. The estimation of selection pressure revealed strong negative selection on the genome fragments obtained in this study and homologous to them ACLSV sequences from the GenBank database. Relationships between the geographic origin and the nucleotide identity of the fragments of ACLSV were not found.
\end{abstract}

Key words: Apple chlorotic leaf spot virus, molecular variability, selection pressure, potential recombination events.

Abbreviations: ACLSV, Apple chlorotic leaf spot virus; CP, coat protein; dN/dS ratio, number of synonymous (dS) and non-synonymous $(\mathrm{dN})$ substitutions per site; FEL, fixed effects likelihood; GARD, genetic algorithm recombination detection; ORF, open reading frame; PARRIS, partitioning approach for robust inference of selection; RT-PCR, reverse transcription polymerase chain reaction; SBP, single breakpoint recombination; SLAC, single-likelihood ancestor counting.

\section{Introduction}

Apple chlorotic leaf spot virus (ACLSV) is a member of Trichovirus genus from the Flexiviridae family (Martelli et al. 2007). It can infect apple, pear, plum, cherry, apricot, peach, and quince (Posnett et al. 1963; Candresse et al. 1995; German et al. 1997). Infected plants are more susceptible to bacterial and fungal diseases, and lower resistance to abiotic stresses (Zawadzka 1989). Mixed viral infections can reduce fruit yields up to 60\% (Campbell 1963; Posnett et al. 1963; Schmidt 1972). Generally the disease is asymptomatic, but deformations, size reduction, and chlorotic spots on leaves can be observed on susceptible apple trees. ACLSV can be transferred by mechanical inoculations, grafting and via vegetative propagation (Németh 1986).

The virus has 640 to $760 \mathrm{~nm}$ long flexious filamentous particles. The single-stranded positive-sence genomic RNA is polyadenylated and encapsidated in coat proteins (CP) of approximately $22 \mathrm{kDa}$ (Yoshikawa, Takahashi 1998). Excluding the poly (A) tail at ACLSV 3'-end, the genome consists of 7474 to 7561 bp (German et al. 1990; Sato et al. 1993; Jelkmann 1996; German et al. 1997; Yaegashi et al. 2007; Marini et al. 2008; Niu et al. 2012). It has three overlapping open reading frames (ORF). ORF 1 encodes a $216 \mathrm{kDa}$ replication-associated protein (Rep), ORF 2 encodes a 50-kDa movement protein, and ORF 3 encodes coat protein CP (Sato et al. 1993). The nucleotide sequences of ACLSV genomes are highly variable. The similarity of 10 complete genomes isolates from different hosts varied from 67.2 to $95.1 \%$ (Niu et al. 2012). Variability in nucleotide sequences of this viral genome was observed even among different isolates from one plant (Candresse et al. 1995). Moreover, divergence levels vary in different regions in ACLSV genome. The results of multiple sequence alignment of the viral ORF structure has shown that the sequence coding coat protein is more conservative in comparison with the sequence coding movement protein (Niu et al. 2012).

The knowledge about the genetic diversity of ACLSV in Belarus is still lacking. The aim of this study was to investigate molecular variability of ACLSV infecting apple trees in Belarusian orchards and estimate their geographical and genetic relations by analysing the nucleotide sequences of ACLSV genome fragments.

\section{Materials and methods}

\section{Plant material}

The study was conducted on samples collected in apple orchards in the Minsk region of Belarus in 2014.

\section{RNA extraction and $R T-P C R$}

RNA extraction from leaf fragments was performed with a Gene JetTM Plant Genomic RNA Purification Mini Kit 
Table 1. Isolates and their GenBank sequence accession numbers

\begin{tabular}{lccc}
\hline Isolate code & Apple cultivar & Host plant origin region & GenBank accession No. \\
ACLSV_rep/mp_Antey_5/6_sam & 'Antei' & Minsk & KP994184 \\
\hline ACLSV_rep/mp_Belsad_12/22_sam & Unknown & Minsk & KP994185 \\
ACLSV_rep/mp_Elena_37/31_sam & 'Elena' & Minsk & KP994186 \\
ACLSV_rep/mp_Elena_37/32_sam & 'Elena' & Minsk & KP994187 \\
ACLSV_rep/mp_Krasavita_3/25_sam & 'Krasavitsa' & Minsk & KP994188
\end{tabular}

(Thermo Scientific, EU). The synthesis of minus-strands of cDNA was conducted with a Revert AidTM HMinus First Srtandc DNA Synthesis Kit (Thermo Scientific, EU) according to the recommended protocol. Fragments of viral genomes were amplified with ACLSV F5 and ACLSV R5 primers according to Niu et al. (2012). Amplicons were separated by electrophoresis on $2 \%$ agarose gels in $1 \times$ TAE buffer and stained with ethidium bromide. 100 bp DNA Ladder Plus (Thermo Scientific, EU) was used as molecular weight marker.

\section{Cloning and sequencing}

After electrophoretic separation the PCR products from individual samples were eluted from the agarose gel by a Gene JetTM Gel Extraction Kit (Thermo Scientific, EU) and ligated in $\mathrm{pTZ} 57 \mathrm{R} / \mathrm{T}$ vector. The ligated product was transformed in E.coliDH5a with an Ins TAcloneTM PCR Cloning Kit (Thermo Scientific, EU) and transformants were cultivated on LB-Amp medium. The plasmid DNA was purified with a Plasmid Gene JetTM Miniprep Kit (Thermo Scientific, EU) according to the manufacturer's protocol. The PCR products were sequenced with M13 universal primers and a BigDye Terminator v3.1 Cycle Sequencing Kit (Applied Biosystems). Amplification for sequencing and purification of the obtained products were performed

\section{Data analysis}

Sequence data were analysed using Geneious 7 software (trial version). The obtained sequences were compared with viral sequences (or their fragments if they were longer than our sequences) available in GenBank on April, 2016.

Multiple alignments were performed with the algorithm CLUSTAL W (Thompson et al. 1994). Comparative analyses of the sequence alignments were carried out in Datamonkey (Kosakovsky Pond, Frost 2005a). HKY85 was used as the nucleotide substitution bias model in all studies. Methods of single breakpoint recombination (SBP) and genetic algorithm recombination detection (GARD) were used to find evidence of recombination events (Kosakovsky Pond et al. 2006a, Kosakovsky Pond et al. 2006b). The algorithm fixed effects likelihood (FEL) FEL and single-likelihood ancestor counting (SLAC) SLAC were used to estimate the $\mathrm{dN} / \mathrm{dS}$ (or $\omega$ ) ratio of each codon in the alignment (Kosakovsky Pond, Frost 2005b). These methods can take recombination into account, and therefore results of GARD analyses were used in this study. The algorithm partitioning approach for robust inference of selection (PARRIS) was used to confirm that the maximum likelihood inference of positive selection was reliable to clarify the presence of recombination (Scheffler et al.2006). These methods (SLAC, FEL and PARRIS) were used at $p$ value 0.1 . The GABranch method was used to evaluate the selection pressure by grouping branches of a phylogenetic tree according to the omega values (Kosakovsky Pond, Frost 2005). Phylogenetic trees constructed with Neighbor-Joining method were used for this analysis.

\section{Results}

Five ACLSV isolates obtained from infected apple trees were sequenced (Table 1) The genome region coding the fragments of two overlapping ORF was studied. The first ORFs encodes the replicase and the second one encodes movement protein. The length of the obtained sequences was $850 \mathrm{bp}$. The sequence similarity between them ranged from 98.6 to $84.2 \%$. The comparison with the reference sequence NC_001409.1 from GenBank showed that the 1-732 and 644-850 nucleotides correspond to the 4923-5655 nucleotides of the replicase gene and the 1-207 nucleotides corresponds to the movement protein, respectively.

\section{Replicase gene}

A potential recombination event was identified in the 636 position using the SBP algorithm, while using GARD algorithm two sites were found in the 237 and 405 positions ( $p=0.05$; Fig. 1$)$. The data obtained by both methods were used to evaluate a selection pressure. Both SLAC and FEL methods did not suggest that the codons are under positive selection. The number of sites under negative selection

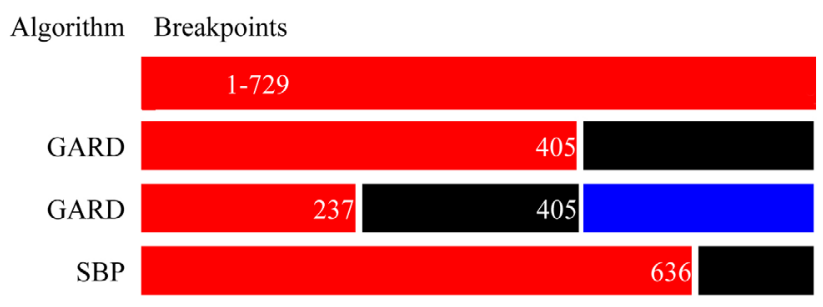

Fig. 1. GARD and SBP analyses identified possible recombination sites within the fragment of ACLSV replicase gene ASPV CP sequences at positions 237 and 405 and position 636, respectively. 
calculated by different methods varied from 167 to 180 (Table 2). The algorithm PARRIS has confirmed absence (at $p<0.1$ ) of positive selection signals. The evolution of the individual branches in the phylogenetic tree occurs for $\mathrm{dN} /$ dS $<1$ according to the GABranch results (Fig. 2), which suggests that purifying selection dominates in the case of the ACLSV replicase.
Table 2. Number of the sites under negative selection in ACLSV fragments

\begin{tabular}{lcc} 
Method used & $\begin{array}{c}\text { ACLSV replicase } \\
\text { fragment }\end{array}$ & $\begin{array}{c}\text { ACLSV movement } \\
\text { protein fragment }\end{array}$ \\
\hline FEL & 180 & 38 \\
SLAC & 167 & 32
\end{tabular}

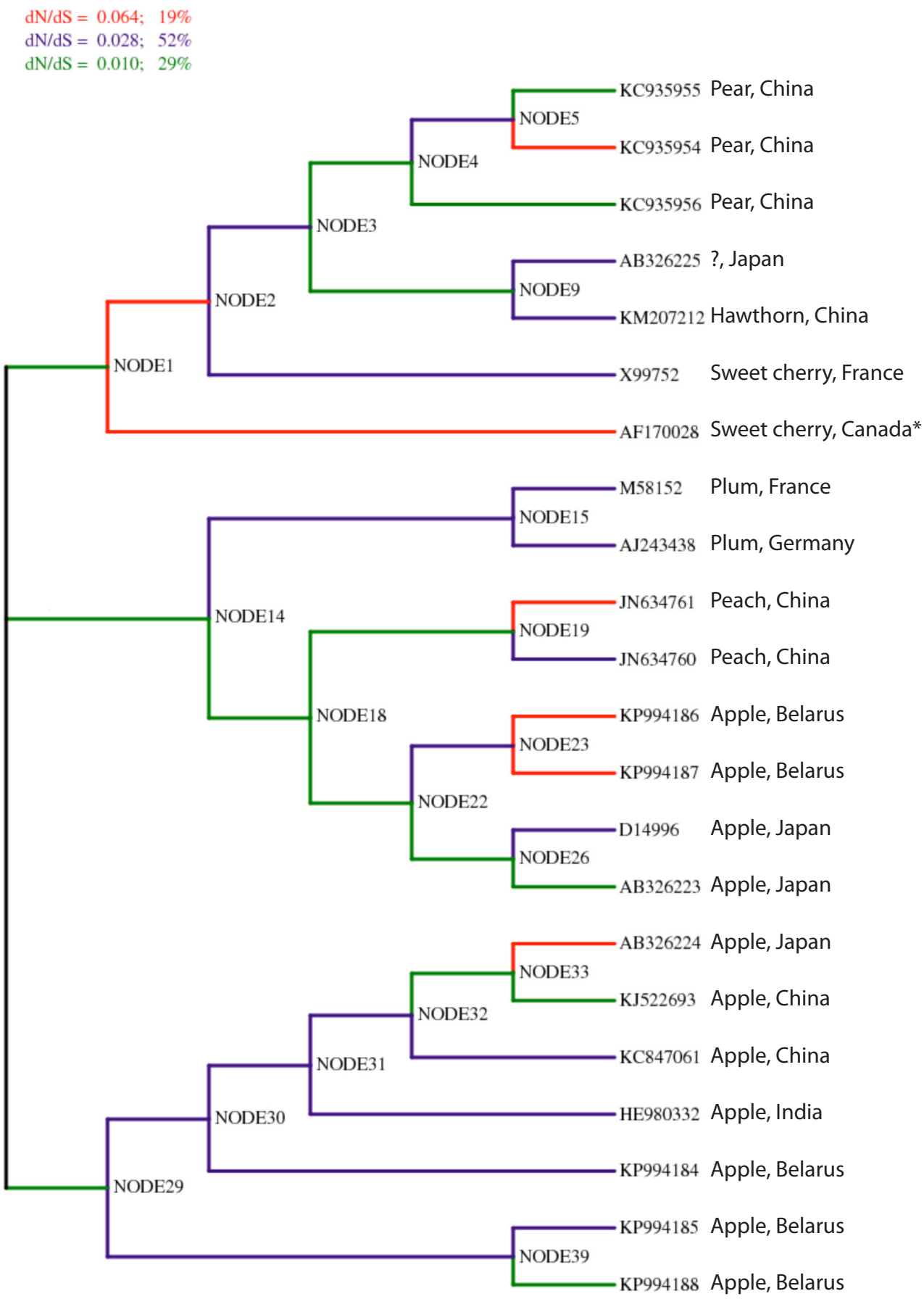

Fig. 1. GARD GABranch analysis of ACLSV replicase gene fragment showing the Neighbor-Joining tree with $\mathrm{dN} / \mathrm{dS}$ ratio coded by colour. Red branches represent the highest omega values, while purple and green branches indicate medium and low values, respectively. All values in this GABranch analysis show $\mathrm{dN} / \mathrm{dS}$ ratio below 1, suggesting strong purifying selection forces during the history of the ACLSV replicase gene. The isolate of Cherry mottle leaf virus is marked with symbol *. 
The Neighbor-Jonining tree presented in Fig. 2 was built with partial sequences of the ACLSV replicase, 5 and 17 of them were obtained from this research and GenBank, respectively. All these sequences are divided into three groups. Group I contains the pear, hawthorn, and cherry isolates and one from an unknown host plant. Group II includes the plum, apricot and apple isolates, two of which were obtained in this study. Group III contains only apple isolates, including three isolates under study. A relationship between the degree of sequence similarity and geographic location of host plant were not detected.

\section{Movement protein gene}

A potential recombination site was found in the fragment of the ORF encoding the movement protein. The algorithms GARD and SBP showed its location in position 67 and 87, respectively (Fig. 3). The evaluation of selective pressure shows that these nucleotide sequences are not under positive selection. The number of sites under negative selection varied from 32 to 38 , depending on the calculations by methods used (Table 2). The PARRIS algorithm did not show signals of positive selection at $p<0.1$. GABranch analysis shown that all branches of the Neighbor-Joining tree evolved at a value of $\mathrm{dN} / \mathrm{dS}=0.034$. The low values of $\mathrm{dN} / \mathrm{dS}$ suggest that purifying selection occurred during the studied historical period of the ACLSV movement protein.

\section{Discussion}

High genetic diversity of RNA viruses was found to result from high frequency of spontaneous mutations $\left(10^{-6}\right.$ to $10^{-4}$ substitutions per nucleotide per genome copy) (Combe, Sanjuan 2014). Therefore, the population of RNA viruses can exist as a mixture of various mutant genotypes (Doningo 2002). A high mutation rate may be considered as the adaptive ability that allows viruses to adapt rapidly to numerous host species within a kingdom (Schneider, Roossinck 2001).

The fragments of viral genomes isolated in Belarus showed high genetic variability. Minimal nucleotide similarity of fragments sequenced from apple varieties was $84.2 \%$. The results obtained in other studies also indicated the significant genetic diversity of this virus. Similarity of two ACLSV complete genome sequences obtained in China was estimated to be $95.1 \%$ (Niu et al. 2012). The study of

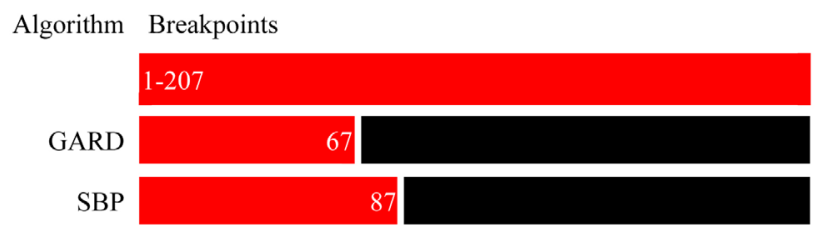

Fig. 3. GARD and SBP analyses identified possible recombination sites within the fragment of ACLSV movement protein gene sequences at positions 67 and 87, respectively. the genetic diversity of pome fruit viruses in Latvia showed that ten ACLSV isolates had sequence similarity of 77.5 to 97.4\% in their 3' terminal region (Pūpola et al. 2011).

The estimation of selection pressure on the ACLSV genome fragments revealed that they undergo the strong negative selection. Studies conducted in different countries showed that purifying selection dominates in the cases of viruses infecting apple trees, but individual nucleotides or viral genome regions may be under positive selection (Komorowska et al. 2011; Liebenberg et al. 2012; Liu et al. 2014; Yoon et al. 2014). Perhaps, the negative selection pressure can be explained by the participation of a single viral protein in numerous processes. For example, beside the formation of viral particles in a host plant, the viral coat proteins are involved in the replication of viral nucleic acids, movement of viral particles from one cell to another, symptom formation, suppression of RNA silencing, and systemic spread of the virus in a host plant (Callaway et al. 2001; Lu et al. 2004; Yaegashi et al. 2007). Such multifunctionality suggests that a set of amino acids in a protein are crucial for the vitality of virus. This imposes certain restrictions on the ability to maintain viability for the mutant genotypes.

Several factors depends on the direction of natural selection. One of them is the means of viral spread. It was shown that the $\mathrm{dN} / \mathrm{dS}$ ratio in the sequences of the surface structural proteins (envelope glycoprotein or outer capsid) of transmissible human viruses was lower than in the sequences of viruses transmitted by other means. Similar results were obtained for genes encoding the envelope proteins of plant viruses (Chare, Holmes 2004). The host immune system also affects the direction of natural selection. Animal viruses were found to be under positive selection (Drummond et al. 2003). Perhaps, the absence of this factor for plant viruses leads to lack of need for continuous changes in surface structures.

Attempts to find a relationship between geographic origin and nucleotide identity of pome fruit virus genome fragments have repeatedly been performed by researchers from various scientific centers. However, strong relations among samples with a similar geographical origin were not observed, despite the considerable variability in viral genomes (Liebenberg et al. 2012; Liu et al. 2014; Valasevich et al. 2015), also in our study (Fig. 1). Perhaps, such a pattern is formed by the action of strong purifying selection which is typical for plant viruses. Similarity between isolates from the same host plant is observed much more frequently, although it is not always (Komorowska et al. 2011; Liebenberg et al. 2012; Liu et al. 2014; Valasevich et al. 2015).

Such a pattern was observed in our study during investigation of phylogenetic relationships for the ACLSV isolates, althought the observed pattern was not distinct. Two of the three clusters in ACLSV phylogenetic tree are mixed, i.e., some isolates from the genus Malus form 
a separate cluster but the other are grouped with isolates of plum and apricot. Perhaps, such a pattern was caused by vertical virus transmission between different plant species, as observed in Shaanxi, China, where evidence of recombination processes between ACLSV isolates was found for different host plants (Liu et al. 2014). The potential sites of recombination were identified in the sequences of the replicase and movement protein genes of ASLSV in our study. However, the localization of the sites in ASLSV sequences depended on the algorithms used. Perhaps, this difference occurred due to the processes of recombinations in viral genomes a long time ago, or due to lack of precission of the methods used.

\section{References}

Callaway A., Giesman-Cookmeyer D., Gillock E.T., Sit T.L., Lommel S.A. 2001. The multifunctional capsid proteins of plant RNA. Annu. Rev. Phytopathol. 39: 419-460.

Campbell A.I. 1963. The effect of some latent virus infections of the growth and cropping apples. J. Hortic. Sci. 38: 15-19.

Candresse T., Lanneau M., Revers F., Grasseau N., Macquaire G., German S., Malinowski T., Dunez. J. 1995. An immunocapture PCR assay adapted to the detection and the analysis of the molecular variability of the Apple chlorotic leaf spot virus. Acta Horticult. 386: 136-147.

Chare E.R., Holmes E.C. 2004. Selection pressures in the capsid genes of plant RNA viruses reflect mode of transmission. J. Gen. Virol. 2004: 3149-3157.

Combe M., Sanjuan R. 2014. Variation in RNA virus mutation rates across host cells. PLOS Pathogens 10: 1-7.

Doningo E. 2002. Quasispecies theory in virology. J. Virol. 76: 463-465.

Drummond A., Pybus O.G., Rambaut A. 2003. Inference of viral evolutionary rates from molecular sequences. Adv. Parasitol. 54: 331-358.

German S., Candresse T., Lanneau M., Huet J.C., Pernollet J.C., Dunez J. 1990. Nucleotide sequence and genomic organization of Apple chlorotic leaf spot closterovirus. Virology 179: 104-112.

German S., Delbos R.P., Candresse T., Lanneau M., Dunez J. 1997. Complete nucleotide sequence of the genome of a serve cherry isolate of Apple chlorotic leaf spot tricho virus (ACLSV). Arch. Virol. 142: 833-841.

Hassan M., Myrta A., Polak J. 2006. Simultaneous detection and identification of four pome fruit viruses by one-tube pentaplex RT-PCR. J. Virol. Methods 133: 124-129.

Jelkmann W. 1996. The nucleotide sequence of a strain of Apple chlorotic leaf spot virus (ACLSV) responsible for plum pseudopox and its relation to an apple and plum bark split strain. Phytopatology 86: 101.

Komorowska B., Siedlecki P., Kaczanowski S., Hasiów-Jaroszewska B., Malinowski T. 2011. Sequence diversity and potential recombination events in the coat protein gene of Apple stem pitting virus. Virus Res. 158: 263-267.

Kosakovsky Pond S.L., Frost S.D.W. 2005a. Datamonkey: rapid detection of selection pressure on individual sites of codon alidnments. Bioinformatics 21: 2531-2533.

Kosakovsky Pond S.L., Frost S.D.W. 2005b. A genetic algorithm approach to detecting lineage-specific variation in selection pressure. Mol. Biol. Evol. 22: 478-485.
Kosakovsky Pond S.L., Frost S.D.W. 2005c. Not so different after all: a comparison of methods for detecting amino acid sites under selection. Mol. Biol. Evol. 22: 1208-1222.

Kosakovsky Pond S. L., Posada D., Gravenor M. B., Woelk C. H., Frost S.D.W. 2006a. Automated phylogenetic detection of recombination using a genetic algorithm. Mol. Biol. Evol. 23: 1891-1901.

Kosakovsky Pond S.L., Posada D., Gravenor M.B., Woelk C.H., Frost S.D.W. 2006b. GARD: a genetic algorithm for recombination detection. Bioinformatics 22: 3096-3098.

Liebenberg, A., Moury B., Sabath N., Hell R., Kappis A., Jarausch W., Wetzel T. 2012. Molecular evolution of the genomic RNA of Apple stem grooving capillovirus. J. Mol. Evol. 75: 92-101.

Liu P., Li Z., Song S., Wu Y.Y. 2014. Molecular variability of Apple chlorotic leaf spot virus in Shaanxi, China. Phytoparasitica 42: 445-454.

Lu R., Folimonov A., Shintaku M., Li W.-X., Falk B.W., Dawson W.O., Ding S.-W. 2004. Three distinct suppressors of RNA silencing encoded by a $20-\mathrm{kb}$ viral RNA genome. Proc. Nat. Acad. Sci. USA 101: 15742-15747.

Marini D.B., Gibson B.G., Scott S.W. 2008. The complete nucleotide sequence of an isolate of Apple chlorotic leaf spot virus from peach (Prunica persica (L.) Batch). Arch. Virol. 153: 1003-1005.

Martelli G.P., Adams M.J., Kreuze J. F., Dolja V.V. 2007. Family Flexiviridae: a case study in virion and genome plasticity. Annu. Rev. Phytopathol. 45: 73-100.

Németh M. 1986. Virus, Mycoplasma, and Rickettsia Diseases of Fruit Trees. Akadémiai Kiádo, Budapest. 841 p.

Niu F., Pan S., Wu Z., Jiang D., Li S. 2012. Complete nucleotide sequences of the genomes of two isolates of Apple chlorotic leaf spot virus from peach (Prunus persica) in China. Arch. Virol. 157: 783-786.

Posnett A.F., Cropley R., Ellenberger C.E. 1963. The effect of virus infection on the growth and cropp of apple, pear and plum trees. Phytopathol. Mediter. 2: 158-161.

Pūpola N., Moročko-Bičevska I., Kāle A., Zeltiņš A. 2011. Occurrence and diversity of pome fruit viruses in apple and pear orchards in Latvia. J. Phytopathol. 159: 597-605.

Sato K., Yoshikawa N., Takahashi T. 1993. Complete nucleotide sequence of the genome of an apple isolate of Apple chlorotic leaf spot virus. J. Gen. Virol. 74: 1927-1931.

Scheffler K, Martin D.P., Seoighe C. 2006. Robust inference of positive selection from recombining coding sequences. Bioinformatics 22: 2493-2499.

Schmidt H. 1972. The effect of 'latent' virus infections on the yield of maiden trees on 20 apomictic apple seedling root-stocks. J. Hortic. Sci. 47: 159-163.

Schneide W.L., Roossinck M.J. 2001. Genetic diversity in RNA virus quasispecies is controlled by host-virus interactions. J. Virol. 75: 6566-6571.

Thompson J.D., Higgins D.G., Gibson T.J. 1994. CLUSTAL W: improving the sensitivity of progressive multiple sequence alignment through sequence weighting, position-specific gap penalties and weight matrix choice. Nucl. Acids Res. 22: 4673-4680.

Valasevich N., Cieslinska M., Kolbanova E. 2015. Molecular characterization of Apple mosaic virus isolates from apple and rose. Eur. J. Plant Pathol. 141: 839-845.

Yaegashi H., Isogai M., Tajima H., Sano T., Yoshikawa N. 2007. Combinations of two amino acids (Ala40 and Phe75 or Ser40 and Tyr75) in the coat protein of Apple chlorotic leaf spot virus 
are crucial for infectivity. J. Gen. Virol. 88: 2611-2618.

Yoon J.Y., Joa J.H., Choi K.S., Do K.S., Lim H.C., Chung B.N. 2014. Genetic diversity of a natural population of Apple stem pitting virus isolated from apple in Korea. Plant Pathol. J. 30: 195-199. Yoshikawa N., Takahashi T. 1998. Properties of RNAs and proteins of Apple stem grooving and Apple chlorotic leaf spot viruses. J. Gen. Virol. 88: 2611-2618.

Zawadzka B. 1989. The influence of virus and mycoplasma diseases on frost damage of apple trees. Acta Horticult. 235: 59-67. 